\title{
Thoughts on Pain Management, Postoperative Nausea and Vomiting (PONV) \& Brain Fog
}

\author{
Barry Friedberg* \\ Goldilocks Anesthesia Foundation, USA
}

Submission: February 19, 2017; Published: March 14, 2017

*Corresponding author: Barry Friedberg, President and founder of Goldilocks Anesthesia Foundation, Email: narkose0126@gmail.com

\section{Introduction}

Persistent anesthesia problems may be summarized as overand under-medication, pain management, and postoperative nausea and vomiting (PONV).

\section{Over- \&Under-Medication}

Prior to the 1996 FDA approval of a direct cortical responsemonitor (DCRM), determination of anesthetic dose relied on body weight, medical \& physical assessment (i.e. ASA status), and heart rate (HR) and blood pressure (BP) changes, especially thesevital signs changes occurring with initial incision.

The cerebral cortexis the target of anesthetics. The adult brain weighs approximately 3-4 pounds and doesn't vary substantially with body weight.Average body weight doses based on the ' $70 \mathrm{~kg}$ ' patient will likely over or under-medicate many patients. ASA status is also an unlikely guide to individual cortical responses to body weight based drug doses.

Pharmacokinetics (PK) and pharmacodynamics (PD) as well as target controlled infusion (TCI) are alternative, yet indirect, measures of cortical response by way of predicting anesthetic blood levels. These approaches would be acceptable if blood levels, not the cortex, were the anesthetics' target.

Vital signs (i.e. HR and BP) are brain stem functions. The American Society of Anesthesiologists' (ASA) awareness with recall study showed that half of patients who experienced awareness had no change in either HR or BP with which to alert their anesthesiologist [1]. This finding was not an especially surprising since consciousness, memory and pain perception are cortical, not brain stem, functions.

Under-medication is estimated to occur in only $0.1 \%$ of patients and may result in PTSD in them. Unpleasant an experience as awareness with recall can be, there are no documented cases of death from anesthesia awareness. Many of the remaining $99.9 \%$ of patients may be subjected to routine over-medication (Figure 1).

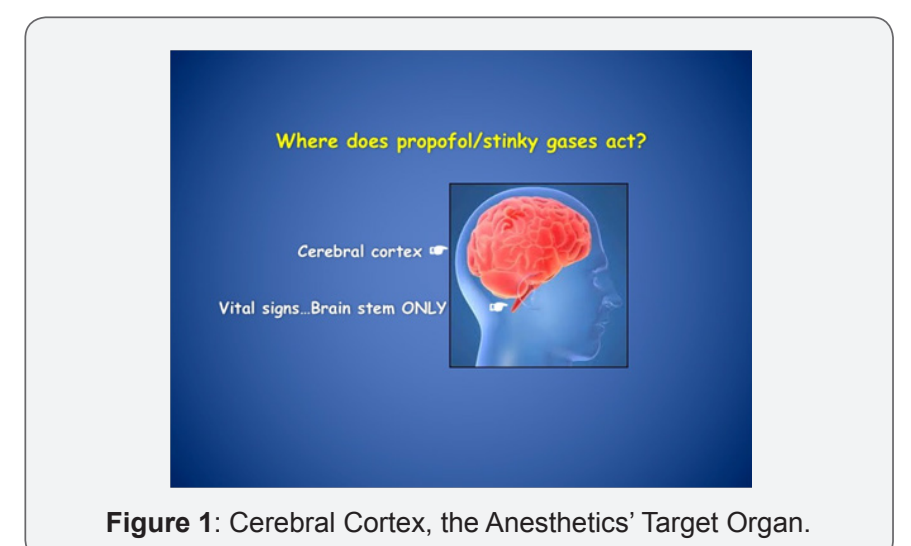

Not only does one American patient every day perish (mortality) from anesthesia over-medication but also $16 \mathrm{M}$ of the $40 \mathrm{M}$ patients (40\%) every year emerge with 'brain fog' (morbidity) [2]. Brain fog may be defined as delayed anesthetic emergence, but also can include postoperative cognitive dysfunction (POCD) or even delirium [3-5].

Postop brain fog creates additional morbidity while adding substantial additional costs to the health care system caring for patients who cannot be quickly processed and discharged from the system. Additionally, patients must endure the long-term consequences of their anesthesiologists' short term care.

The DCRM has been validated in over 3,500 published studies and can be found in $75 \%$ of US hospitals. The question remains 'why is directly measuring the organ being medicated with a DCRM monitor only routinely done $25 \%$ of the time?'

Part of the answer may lie in the manner in this monitor was originally configured. On a unit-less scale of 0-100, the lower the number, the more sedated the patient. This number is a derived, not directly measured, value. The 15-30-second delay from real time places the anesthesiologist in the unfavorable position of catching up to patient needs instead of being able to anticipate 
them. This creates a situation like trying to drive one's car with only the rearview mirror's information, not especially safe or useful (Figure 2).

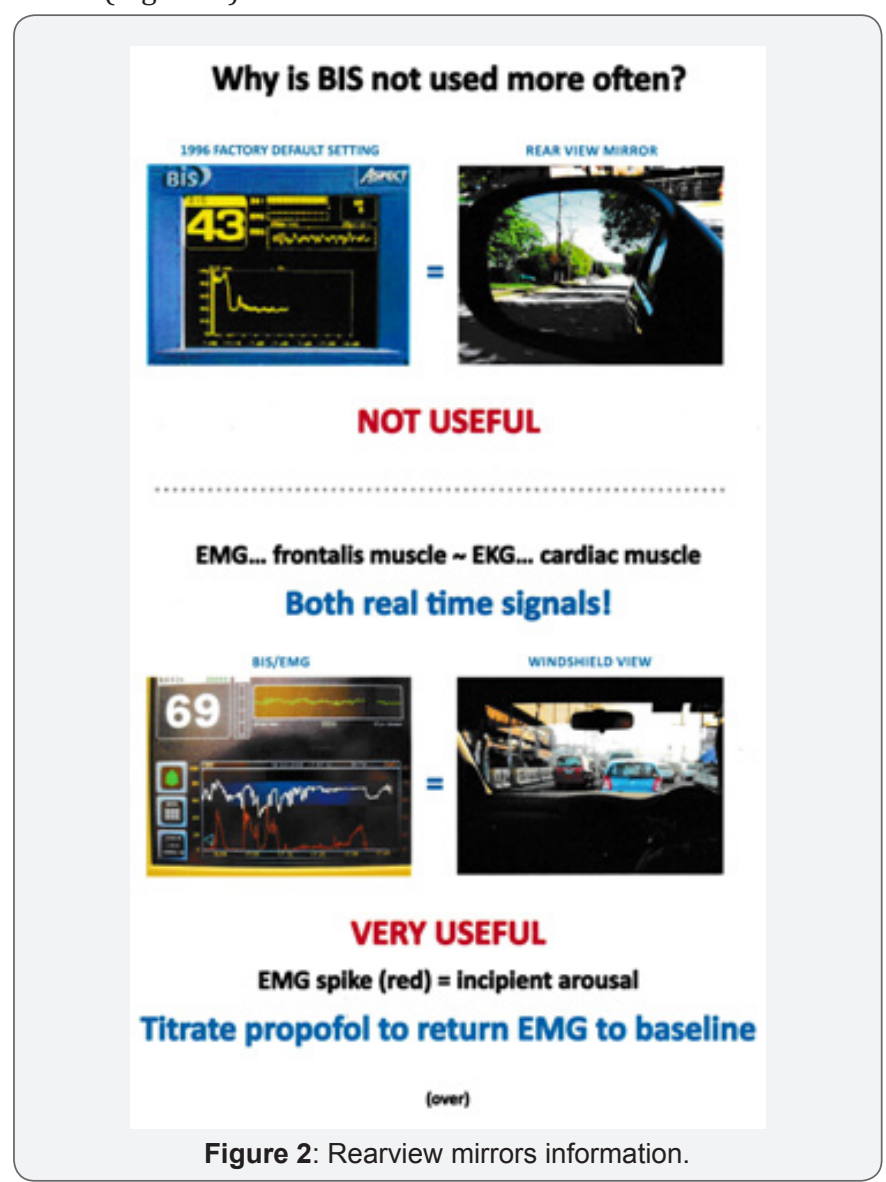

The first anesthesia textbook with a DCRM monitor on its cover also displayed the electromyogram (EMG) of the frontalis muscle (akin to the EKG of the cardiac muscle) in the picture (Figure 3). The text described the utility of this real-time signal; i.e. EMG spikes signal incipient arousal and the need to proactively increase sedation to return the EMG to baseline [6]. All that is needed to display the EMG is to use the existing software to select and save it as the secondary trend.

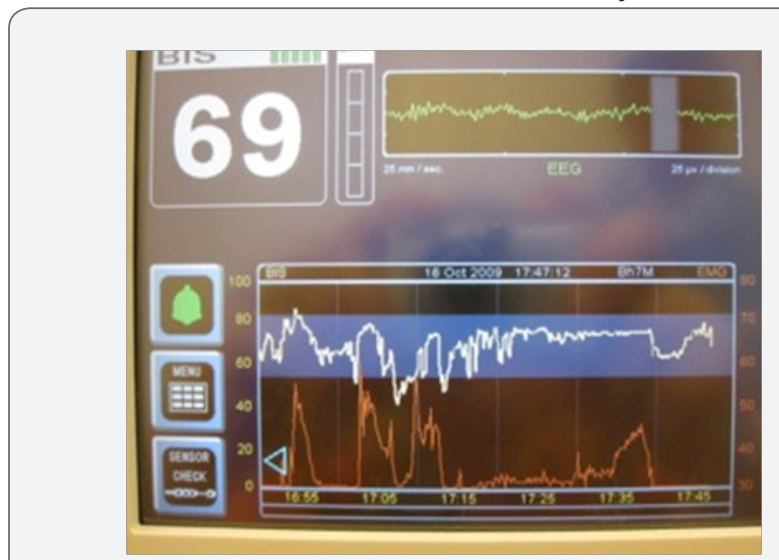

Figure 3: Direct cortical monitor (DCRM) with electromyogram (EMG) as secondary, lower, trend (red).
Most patients achieve propofol sedation adequate enough to prevent awareness and recall at $60<\mathrm{BIS}<75$ (with baseline EMG) level of with 25-50 $\mathrm{mcg}^{-1} \cdot \mathrm{kg}^{-1}$.min. Over 18-years' experience titrating propofol with DCRM, variation of as little as $2.5 \mathrm{mcg}^{-1}$ . $\mathrm{kg}^{-1}$. min and as much as $200 \mathrm{mcg}-1 . \mathrm{kg}^{-1}$. min has been observed to achieve the same level of amnesia and sedation. 'Apples' to 'apples' comparisons between patients, despite the nearly hundred-fold observed variation in propofol requirements to achieve, become more meaningful when using numerically based definitions of levels of consciousness achieved [7].

Postoperative brain fog likely is a multi-factorial problem. Until universal DCRM monitoring becomes a standard of care, it will not be possible to clarify the role routine over-medication plays [8]. It is unlikely beneficial for elderly patients to routinely administer $30 \%$ more than what is needed to achieve $60<\mathrm{BIS}<75$. Common sense is uncommon (Figure 4) - Voltaire.

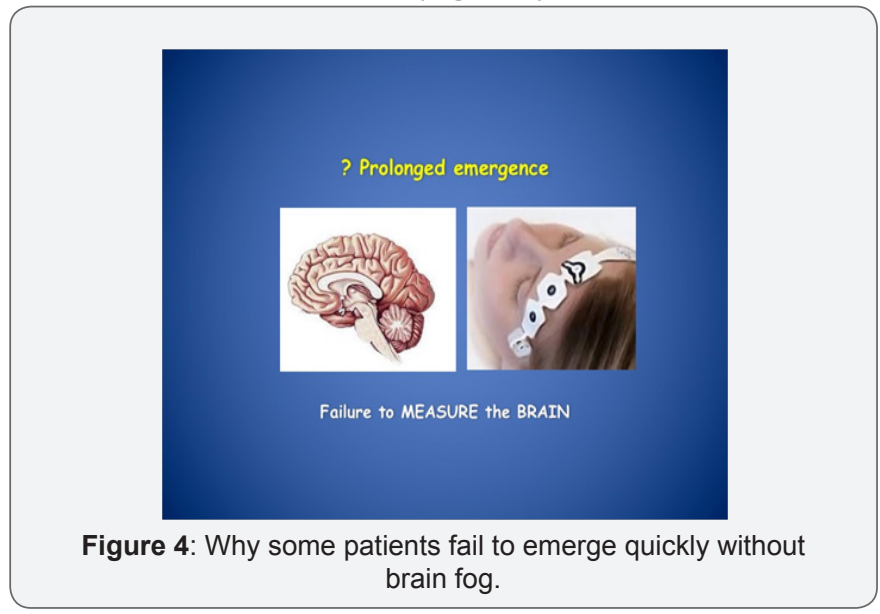

\section{Pain management}

Most people know it does no good to close the barn door after the horses have escaped. But too many anesthesiologists still need to be convinced that it's futile to try to prevent postop pain by allowing surgeons to cut without first blocking the midbrain N-methyl, D-aspartate (NMDA) receptors $[9,10]$.

Local anesthetic skin injection or incision is an extremely potent signal to the brain that the "world of danger" has invaded the "protected world of self." The sedated brain can't differentiate between the mugger's knife and the surgeon's scalpel (or trocar). While there are certainly other internal pain receptors, no signal is more determinant of post-operative pain than of skin incision (or skin injection). An unprotected incision sets off the major cortical alarmsthat initiate the wind-up phenomenon.

Surgery is a painful experience.Most anesthesiologistsbelieve acardinal function is the prevention of pain during surgery. From 1975 through 1993, this author had never once considered why there was a need for postop opioid rescue for many, if not most, patients. In 1992, a clinical trial began using 50 mg IV ketamine, 2-3 minutes prior to stimulation AFTER propofol hypnosis to dissociate patients for pre-incisional local anesthesia injection $[11,12]$. 
When propofol is incrementally titrated ketamine hallucinations are eliminated [13]. For elective surgery, customary propofol increments are $50 \mathrm{mcg}^{-1} . \mathrm{kg}$ repeated either to loss of lid reflex/loss of verbal response or to $60<\mathrm{BIS}<75$ with baseline EMG. This DCRM level is usually attained within 2-3 minutes. Starting with such an apparently homeopathic propofol dose quickly allows the anesthesiologist to determine an extremely sensitive patient and avoid prolonged emergence and, likely, less brain fog.

The benefit of incremental induction is creating a stable CNS level of propofol to protect from ketamine side effects, preservation of spontaneous ventilation, maintenance of $\mathrm{SpO}_{2}$, and not creating the difficult airway [14]. Incremental propofol induction most commonly preserves the tone in the masseter, genioglossus and orbicularis oris muscles, maintaining a patent airway. Absent a propofolbolus induction, baseline blood pressureis also maintained.

After observing the first 50 cases emerge without opioid rescue, it was reasonable to concludethe principle reason patients have pain after surgery is that they've had pain during surgery. The lack of opioid rescue continued over the next 1,214 patients [15] and through to the present day of more than a total 6,000 patients.

Dissociation, or immobility to noxious stimulation, results from mid-brain NMDA blockadeImmobility (i.e. dissociation) has beenconsistently observed in 100-pound female patients and 250-pound male patients with the same $50 \mathrm{mg}$ ketamine dose.

Why does the effective dissociative dose of ketamine not appear to be related to body weight? The adult brain weighs approximately 3-4 pounds and doesn't vary with body weight. The midbrain is a very small part of the adult brain, and the NMDA receptors are a very small part of the midbrain. Prestimulation NMDA block denies the cortex the knowledge of the intrusion of the outside world of danger.

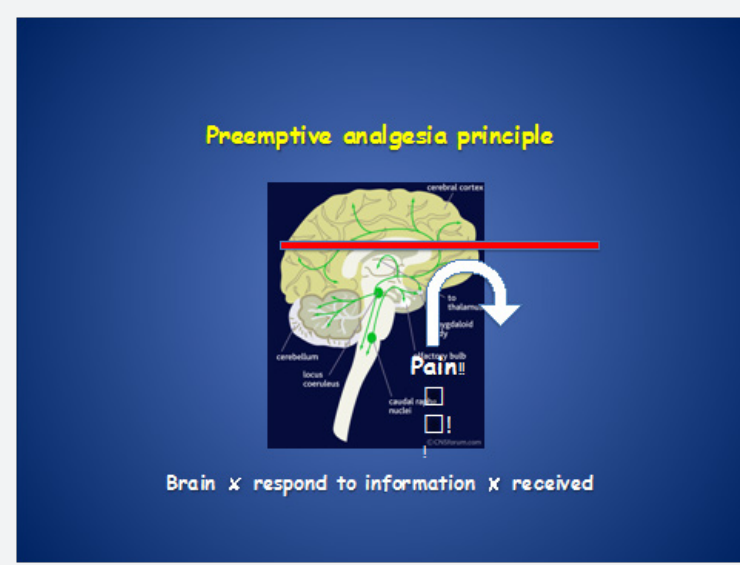

Figure 5: Non-opioid, preemptive analgesia -50mg ketamine 2-3 min pre-injection/incision Dose and timing BOTH critical.
Cognitive dissonance generated by thelack (or dramatically) reduced opioid rescue with pre-stimulation ketamine dose is so great that many, if not most, anesthesiologists will need to observe 10-20 cases to believe them. However, the PACU RNs will notice more quickly. Surgeons and patients' family members will be as impressed as the recovery personnel.Once the patient is protected as described above, the non-opioid, $50 \mathrm{mg}$ ketamine 'miracle' is achievable with propofol sedation, regional analgesia/propofol sedation, and general inhalational anesthesia (Figure 5).

\section{Postoperative Nausea \& Vomiting (PONV)}

Much has been written about postoperative nausea and vomiting (PONV). In 1996, Apfel identified the four most predictive PONV factors; namely, non-smoking, females, history of PONV, planned use of postoperative opioids [16]. Apfel subsequently referenced Friedberg's 1999 study [15] in his PONV chapter $[17,18]$.

Apfel's PONV chapter is number 86 of 89 chapters in Millers' Anesthesia. While patients do not die from PONV, they only wish they were dead. Greater importance to PONV needs to be heeded by our profession as patient satisfaction now plays a role in government and other third party reimbursement.

The data for this five-year review documenting a $0.6 \%$ PONV rate (i.e. 7 of 1,264 patients) were collected by 1997 but not published until 1999 [15]. These patients turned out to be an Apfel-defined high PONV risk patient population that received no anti-emetics! No intra-operative opioids or inhalational ('stinky gases') agent were used [19]. Postoperative opioids were routinely prescribed but rarely used.

Analgesia was provided with adequate local analgesia. Spontaneous ventilation was preserved using only a single respiratory depressant, propofol, and scrupulously avoiding intra-operative opioids. no patients received neuromuscular blocking agents. This left the possibility of patient movement.

Patient movement under sedation is usually the cause for great stress on all involved with the surgery, especially the surgeon who may have pre-operatively injected the operative field with syringes of lidocaine and epinephrine. Observing vasoconstriction, the surgeon (incorrectly) surmises adequate analgesia is present and clamors for more sedation.

The anesthesiologist usually responds with a request for additional analgesia. Tempers rise leading to the inappropriate addition of opioids, benzodiazepines etc. or worse, the abandonment of sedation in favor of general anesthesia (GA) with muscle relaxants. None of these maneuvers treat the movement most accurately.

The presence or absence of an EMG spike on the DCRM enables a dispassionate discussion of what the patient most accurately (and minimally) needs to return the patient to the 
desired motionless condition. In the pre-DCRM era, all patient movement was treated as if it could be awareness and recall. As seen with the headless chicken, a brain is not necessary to generate movement (Figure 6).

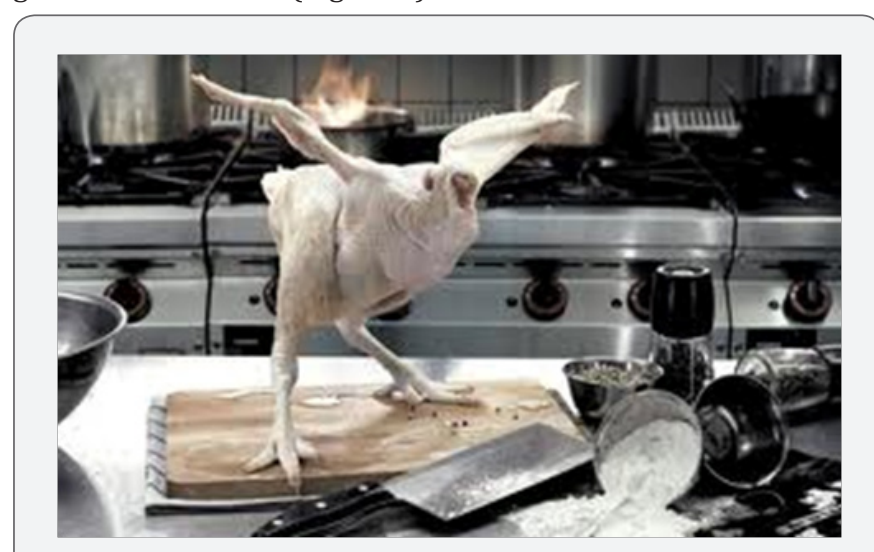

Figure 6: Headless chicken generating movement.

There exists no spinal reflex that can stimulate the EMG of the forehead frontalis muscle. Patient movement without an EMG spike can only be generated by sub-cortical stimulation. This Surgeon's Golden Rules (Table 1) needs the anesthesiologist's time preoperatively with the surgeon to assure success without increasing the known risks of GA. This author believes it is very difficult to accept GA risks for patients having surgery without medical indication; i.e. elective cosmetic surgery. A more enlightened approach is possible using the absence of the EMG spike with patient movement to refute the notion that the patient is 'too light' (Figure 7) (Table 1).

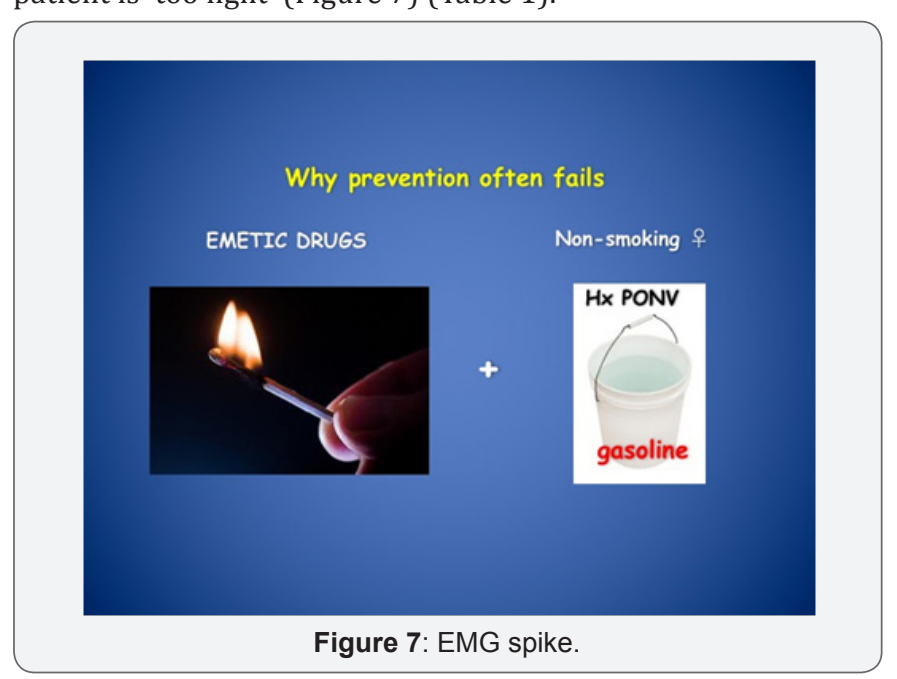

Table 1: The Surgeon's Golden Rules.

\begin{tabular}{|c|c|}
\hline 1. & $\begin{array}{r}\text { Propofol titrated to } 60<\text { BIS }<75 \text { with baseline EMG } \\
\text { means adequate amnesia \& hypnosis }\end{array}$ \\
\hline 2. & $\begin{array}{r}\text { A blanched surgical field is only evidence of } \\
\text { vasoconstriction but not adequate analgesia }\end{array}$ \\
\hline 3. & $\begin{array}{r}\text { Re-inject the immediate area stimulated if patient } \\
\text { movement occurs at } 60<\text { BIS }<75 \text { without } E M G \text { spike }\end{array}$ \\
\hline
\end{tabular}

\section{Conclusion}

When you can measure what you are speaking about, and express it in numbers, you know something about it; but when you cannot measure it, when you cannot express it in numbers, your knowledge is of a meager and unsatisfactory kind; it may be the beginning of knowledge, but you have scarcely, in your thoughts, advanced to the stage of science.

\section{William Thompson, knighted Lord Kelvin.}

Popular lectures and addresses 1891-1894

Less is more. - Mies van Der Rohe

Without direct cortical measurement of anesthetic effect, neither science nor minimally trespassing on patients' physiology will occur. Predictably, problems like over and under-medication, postoperative pain management and PONV will continue to plague anesthesiologists and their patients while incurring avoidable costs. Propofol measurement to $60<\mathrm{BIS}<75$ with baseline EMG obviates the perceived need of the commonly used 2 mg midazolam premedication. Eliminating midazolam also eliminates prolonged emergence in sensitive and/or elderly patients.

Directcortical response measurement enables anesthesiologists to treat patient requirements as the individuals they are as opposed to the $80 \%$ of patients in the middle of the bell curve. Doing so eliminates outliers, transforms every patients' 'mystery' into an 'open book test,' and creates the basis for more humane, cost effective anesthesia care.

Over twenty-five years and in more than 6,000 patients, there has not been a single hospital admission for brain fog, postoperative pain management or PONV. Friedberg's Triad does indeed appear to answer anesthesia's persistent problems.

\section{cknowledgment}

Dr. Friedberg is the president and founder of the nonprofit Goldilocks Foundation. Neither he, nor the foundation, receives financial support from brain monitor makers. Dr. Barry Friedberg has been interviewed extensively about anesthesia and propofol by FOX, CNN, True TV, and People Magazine during the MichaelJackson murder trial. A board-certified anesthesiologist for 39 years, Dr. Friedberg developed propofol ketamine (PK) anesthesia in 1992 and made PKnumerically reproducible with the addition of the anesthesia brain monitor (aka Goldilocks anesthesia) in 1998. He has been published and cited inseveral medical journals and textbooks and was honored with a U.S. Congressional award for applying his methods on wounded soldiers in Afghanistan and Iraq.

\section{References}

1. American Society of Anesthesiologists Task Force on Intraoperative Awareness (2006) Practice Advisory for Intraoperative Awareness and Brain Function Monitoring: A Report by the American Society of Anesthesiologists Task Force on Intraoperative Awareness. Anesthesiology 104(4): 847-864. 
2. Li G, Warner M, Lang BH, Huang L, Sun LS (2009) Epidemiology of Anesthesia-related Mortality in the United States, 1999-2005. Anesthesiology 110(4): 759-765.

3. Monk TG, Weldon BC, Garvan CW, Dede DE, van der Aa MT, et al. (2008) Predictors of Cognitive Dysfunction after Major Non-cardiac Surgery. Anesthesiology 108(1): 18-30.

4. Chan MT, Cheng BC, Lee TM, Gin T (2013) BIS-guided anesthesia decreases postoperative delirium and cognitive decline. J Neurosurg Anesthesiol 25(1): 33-42.

5. Radtke FM, Franck M, Lendner J, Krüger S, Wernecke KD, et al. (2013) Monitoring depth of anaesthesia in a randomized trial decreases the rate of postoperative delirium but not postoperative cognitive dysfunction. Br J Anaesth 110(suppl 1): 98-105.

6. Friedberg B (2007) Anesthesia in Cosmetic Surgery. Cambridge University Press, New York, USA.

7. Friedberg BL (2007) Propofol ketamine with bispectral (BIS) index monitoring. In: Friedberg BL (Ed.), Anesthesia in Cosmetic Surgery. Cambridge University Press, New York, USA, p. 1-13.

8. Friedberg BL (2015) The tree, the forest and standard of care. Br J Anaesth.

9. Paquet M, Tremblay M, Soghomonian, Smith Y (1997) AMPA and NMDA Glutamate Receptor Subunits in Midbrain Dopaminergic Neurons in the Squirrel Monkey: An Immunohistochemical and In Situ Hybridization Study. J Neurosci 17(4): 1377-1396.

10. Friedberg BL (2007) The dissociative effect and preemptive analgesia. In: Friedberg BL (Ed.), Anesthesia in Cosmetic Surgery, Cambridge University Press, New York, USA, p. 39-46.
11. Friedberg BL (1993) Propofol-ketamine technique. Aesthetic Plast Surg 17(4): 297-300.

12. Friedberg BL (2003) Hypnosis first, then dissociation. Anesth Analg 96(3): 913-914.

13. Friedberg BL (1993) Hypnotic doses of propofol block ketamine induced hallucinations. Plast Reconstr Surg 91(1): 196-197.

14. Friedberg BL (2010) The difficult airway in office-based anesthesia. Plast Reconstr Surg 125(5): 222e-223e.

15. Friedberg BL (1999) Propofol-ketamine technique, dissociative anesthesia for office surgery: a five-year review of 1,264 cases. Aesthetic Plast Surg 23(1): 70-75.

16. Apfel CC, Läärä E, Koivuranta M, Greim CA, Roewer N (1999) A simplified risk score for predicting postoperative nausea and vomiting: conclusions from cross-validations between two centers. Anesthesiology 91(3): 693-700.

17. Apfel CC (2010) Postoperative nausea and vomiting. Miller's Anesthesia ( $7^{\text {th }}$ edn), Elsevier, Philadelphia, PA, USA, pp. 2743.

18. Apfel CC (2015) Postoperative nausea and vomiting. Miller's Anesthesia ( $8^{\text {th }}$ edn), Elsevier, Philadelphia, PA, USA, pp. 2961.

19. Friedberg BL (2008) Avoiding emetogenic triggers in the first place is more effective than using anti-emetics. Anesth Analg 106(6): 1921-1922.
Your next submission with Juniper Publishers will reach you the below assets

- Quality Editorial service

- Swift Peer Review

- Reprints availability

- E-prints Service

- Manuscript Podcast for convenient understanding

- Global attainment for your research

- Manuscript accessibility in different formats (Pdf, E-pub, Full Text, Audio)

- Unceasing customer service

Track the below URL for one-step submission https://juniperpublishers.com/online-submission.php 